\title{
Highlights from American Heart Association Annual Scientific Sessions 2009: Orlando, Florida, November 14-18, 2009
}

\author{
Akshay Desai, MD, MPH, and Frederic S. Resnic, MD, MSc
}

The annual scientific sessions of the American Heart Association were held November 14-18, 2009, in Orlando, Florida. This internationally attended meeting was the venue for the release of new clinical trial data as well as an ongoing comprehensive review of many subjects of interest to cardiovascular specialists throughout the world. We provide here a brief overview of some of the most innovative and important developments from the American College of Cardiology scientific sessions.

\section{THERAPIES FOR HEART FAILURE \\ Continuous-Flow Ventricular Assist Devices as \\ Destination Therapy}

The results of the landmark REMATCH trial (Randomized Evaluation of Mechanical Assistance for the Treatment of Congestive Heart Failure), released in 2001, demonstrated a significant survival advantage in transplant-ineligible patients randomized to use of a pulsatile left ventricular assist device (LVAD) as "destination therapy" relative to those managed with optimal medical therapy. ${ }^{1}$ However, 2-year survivals remain suboptimal despite LVAD support $(23 \%$ vs $8 \%$ with medical therapy), and the broader application of LVAD therapy to the population with advanced heart failure has been limited by device size, adverse events (including thromboembolism and infection), and durability.

Second-generation, nonpulsatile VAD designs offer potential advantages over pulsatile VADs with regard to size, patient comfort, and durability and have proven effective as a therapeutic bridge to cardiac transplantation. ${ }^{2}$ Slaughter and colleagues ${ }^{3}$ presented the results of a prospective, randomized comparison of continuous-flow versus pulsatile-flow LVADs in destination therapy, which included 200 transplant-ineligible patients randomly assigned in a 2:1 ratio to receive either a continuous-flow Thoratec HeartMate II (134 patients) (Thoratec Corporation, Pleasanton, Calif) or a pulsatile-flow Thoratec HeartMate XVE device (66 patients). Treatment with the continuous-flow device was associated with a significant improvement in the composite end point of survival at 2 years without disabling stroke or reoperation to replace the device $(46 \%$ vs $11 \% ; P<.001)$, driven largely by the lower rate of device replacement in the

From the Division of Cardiology, Brigham and Women's Hospital, Boston, Mass.

Address for reprints: Frederic S. Resnic MD MSc, the Division of Cardiology, Brig-

ham and Women's Hospital, 75 Francis St, Tower 3B, Boston, MA 02115

(E-mail: fresnic@partners.org).

J Thorac Cardiovasc Surg 2010;139:1090-2

$0022-5223 / \$ 36.00$

Copyright (c) 2010 by The American Association for Thoracic Surgery doi: 10.1016/j.jtcvs.2010.02.002 continuous-flow group. Actuarial survival at 2 years was also significantly improved in the continuous-flow group $(58 \%$ vs $24 \% ; P=.008)$, as were the rates of major adverse events including device-related infection, right heart failure, and rehospitalization for heart failure. No advantage was seen with regard to stroke $(17 \%$ vs $14 \% ; P>.05) .{ }^{3}$ These findings underscore the superiority of continuous-flow LVADs over pulsatile-flow LVADs for the management of heart failure in transplant-ineligible patients.

\section{Treatment of Iron Deficiency to Improve Symptoms in Patients With Heart Failure}

Patients with heart failure may be prone to iron deficiency owing to impaired dietary absorption, depleted iron stores, or defective iron mobilization. Anker and associates ${ }^{4}$ presented the results of the FAIR-HF trial (Ferinject Assessment in Patients with Iron Deficiency and Chronic Heart Failure) with the goal of assessing the impact of intravenous iron treatment on patient-reported symptoms in heart failure. A total of 459 patients with New York Heart Association (NYHA) class II heart failure and a left ventricular ejection fraction of $40 \%$ or less or NYHA class III heart failure and an ejection fraction of $45 \%$ or less, hemoglobin level between 95 and $135 \mathrm{~g} / \mathrm{L}$, and iron deficiency (as assessed by serum ferritin levels) were randomly assigned in a 2:1 ratio to treatment with $200 \mathrm{mg}$ of intravenous ferric carboxymaltose or placebo. At 24 weeks, $50 \%$ of patients in the ironrepletion group and $28 \%$ of controls reported that they were much or moderately improved on the Patient Global Assessment survey (odds ratio 2.51; $P<.001$ ). Similarly, $47 \%$ of iron-treated patients were in NYHA class I or II at week 24 , as compared with $30 \%$ of patients assigned to placebo (odds ratio for improvement by one class, 2.40; $P<.001)$. Significant improvements were also noted in pre-specified secondary end points including 6-minute walk distance and health-related quality of life. Of note, benefits accrued in patients with and without anemia, suggesting that correction of iron deficiency, rather than correction of anemia, may have been responsible.

\section{PHARMACOLOGY AFTER CARDIAC SURGERY No Clinical Benefit of Clopidogrel on Progression of Saphenous Vein Graft (SVG) Disease}

SVG patency rates have been estimated to be approximately $85 \%$ at 1 year ${ }^{5}$ and $50 \%$ at 10 years. ${ }^{6}$ The CASCADE investigators (Cardiac Arrest in Seattle: Conventional Versus Amiodarone Drug Evaluation) undertook a randomized study to determine the effect of clopidogrel $75 \mathrm{mg}$ relative to 


\section{Abbreviations and Acronyms}

LVAD $=$ left ventricular assist device

NYHA $=$ New York Heart Association

PCI = percutaneous coronary intervention

SVG = saphenous vein graft

$\mathrm{VAD}=$ ventricular assist device placebo on vein graft intimal area at 1 year (assessed by intravascular ultrasound) in 112 aspirin-treated patients. SVG patency rates at 1 year were high in both arms of the study (94.3\% for aspirin + clopidogrel vs $93.2 \%$ for aspirin + placebo; $P=.78$ ). Among the 90 patients who received followup intravascular ultrasound assessment, those assigned to clopidogrel had less SVG intimal area than those assigned to aspirin, but this difference did not achieve statistical significance $\left(4.1 \mathrm{~mm}^{2}\right.$ vs $4.9 \mathrm{~mm}^{2}$, reduction $\left.14.8 \% ; P=.21\right)$. No statistical difference in major bleeding was seen between the 2 arms.

\section{No Benefit of Diclofenac on Persistent Pericardial Effusion After Cardiac Surgery}

Pericardial effusion is a common complication of cardiac surgery. Although most effusions resolve spontaneously, postoperative effusions occasionally progress to tamponade and potentially life-threatening compromise of cardiovascular function. The POPE study (Post-Operative Pericardial Effusion) randomized 196 patients with grade 2 to 4 pericardial effusions 1 week after cardiac surgery to treatment with the nonsteroidal anti-inflammatory drug diclofenac $(50 \mathrm{mg}$ bid) or placebo. No difference was observed between the 2 treatment arms in the primary end point of decrement in pericardial effusion grade at 14 days or in the incidence of late tamponade. Of note, however, there was a $10 \%$ incidence of progression to tamponade requiring drainage between postoperative days 20 and 30, highlighting a need to explore alternative surveillance and management strategies for this problem.

\section{ANTIOCOAGULATION WITH DABIGATRAN IN ATRIAL FIBRILLATION}

Primary results of the RE-LY trial (Randomized Evaluation of Long-term anticoagulant therapy), ${ }^{7}$ presented at the European Society of Cardiology 2009 Congress, highlighted the superiority of dabigatran $150 \mathrm{mg}$ over warfarin with regard to prevention of stroke and systemic embolism in 18,113 patients with atrial fibrillation. In an important follow-up analysis, the RE-LY investigators presented data underscoring that the benefits of dabigatran relative to warfarin were maintained even at sites in which the quality of international normalized ratio control (assessed as time in the therapeutic range) was excellent. These data add to the evolving evidence base supporting dabigatran as a promising new alternative to warfarin for stroke prevention in atrial fibrillation. Given the reasonable safety profile for dabigatran and the challenges of successfully maintaining an international normalized ratio in the therapeutic range, dabigatran may represent a major advance for anticoagulation of patients with atrial fibrillation.

\section{CORONARY REVASCULARIZATION IN PATIENT WITH TYPE 2 DIABETES}

The results of the BARI 2D trial (Bypass Angioplasty Revascularization Investigation in Type 2 Diabetes) were presented in which 2368 patients with type 2 diabetes and mild or stable cardiac symptoms were randomized to initial revascularization with optimal medical therapy (with choice of revascularization left to the treating physicians) versus initial medical therapy alone. Overall, the results indicated that 5year mortality was no different between the initial revascularization arm versus initial medical therapy $(11.7 \%$ vs $12.1 \% ; P$ $=.97$ ), although by 5 years $42 \%$ of those patients randomized to medical therapy had crossed over and undergone revascularization. Likewise, there were no significant differences in the rates of major cardiovascular events between the 2 groups. ${ }^{8}$ These results complement the findings of recent trials of optimal medical therapy versus initial revascularization, such as the COURAGE study (Clinical Outcomes Utilizing Revascularization and Aggressive Drug Evaluation), for stable coronary patients ${ }^{9}$ within a higher risk, diabetic population.

\section{ANTIPLATELET PHARMACOLOGY: THERAPIES BEYOND CLOPIDOGREL}

The 12-month results of the PLATO trial (PLATelet inhibition and patient Outcomes in patients with acute coronary syndromes) were presented by Dr P. Gabriel Steg (see Wallentin and associates ${ }^{10}$ ), comparing the oral, reversible, P2Y12 platelet antagonist, ticagrelor, to clopidogrel in over 18,000 patients being treated for acute coronary syndromes. Ticagrelor provides a rapid onset of platelet inhibition and is reversibly bound to platelets, resulting in functional recovery of circulating platelets in approximately 48 hours. The study found that ticagrelor provided a $16 \%$ reduction in the risk of death from vascular causes, myocardial infarction, or stroke by 12 months as compared with the clopidogrel group $(9.8 \%$ vs $11.7 \% ; P<.001)$. This finding was evident by 30 days and sustained to 12 months. Major bleeding did not differ between the ticagrelor and clopidogrel treated groups, and there was no significant differences in bleeding among the $4.5 \%$ of patients who underwent coronary artery bypass grafting as part of the study. ${ }^{10}$ However, given the reversibility of the study drug, it is anticipated that platelet function should return to baseline levels within 48 hours of treatment, suggesting more rapid ability to perform bypass grafting for those patients who require urgent surgical revascularization, as compared with clopidogrel. 
Two studies of the short-acting, intravenous P2Y12 platelet-inhibitor, cangrelor, were presented during the scientific sessions. The CHAMPION PCI trial (Cangrelor versus Standard Therapy to Achieve Optimal Management of Platelet Inhibition) randomized 8877 patients undergoing percutaneous coronary intervention (PCI) to receive either cangrelor or clopidogrel before the $\mathrm{PCI}$ (with all patients receiving standard clopidogrel after the PCI procedure). The investigators found no advantage for cangrelor, either in reducing ischemic events or in the rates of post-procedural bleeding. ${ }^{11}$ The results of the CHAMPION PLATFORM trial, which studied 5362 patients with acute coronary syndrome undergoing PCI and randomized patients to receive cangrelor or placebo before the procedure, with both populations treated with clopidogrel after the PCI procedure, were similar. CHAMPION PLATFORM found no significant reduction in the end point of death, myocardial infarction, or urgent revascularization as compared with placebo, although there was a reduction in the rates of stent thrombosis in patients treated with pre-procedure cangrelor as compared with placebo. ${ }^{12}$ The specific role for cangrelor, if approved for use in the United States, remains uncertain and requires further testing in subgroups of patients.

\section{References}

1. Rose EA, Gelijns AC, Moskowitz AJ, Heitjan DF, Stevenson LW, Dembitsky W, et al. Long-term mechanical left ventricular assistance for end-stage heart failure. N Engl J Med. 2001;345:1435-43.
2. Miller LW, Pagani FD, Russell DS, John R, Boyle AJ, Aaronson KD, et al. Use of a continuous-flow device in patients awaiting heart transplantation. N Engl J Med. 2007;357:885-96.

3. Slaughter MS, Rogers JG, Milano CA, Russell SD, Conte JV, Feldman D, et al. Advanced heart failure treated with continuous-flow left ventricular assist device. N Engl J Med. 2009;361:2241-51.

4. Anker SD, Comin Colet J, Filippatos G, Willenheimer R, Dickstein K, Drexler H, et al. Ferric carboxymaltose in the treatment of iron deficient chronic heart failure patients with or without anemia. N Engl J Med. 2009;361:2436-48.

5. Desai ND, Cohen EA, Naylor CD, Fremes SE. Radial Artery Patency Study Investigators. A randomized comparison of radial-artery and saphenous-vein coronary bypass grafts. $N$ Engl J Med. 2004;351:2302-9.

6. Bourassa MG, Campeau L, Lesperance J, Grondin CM. Changes in grafts and coronary arteries after saphenous vein aortocoronary bypass surgery: results at repeat angiography. Circulation. 1982;65:90-7.

7. Connolly SJ, Ezekowitz MD, Yusuf S, Eikelboom J, Oldgren J, Parekh A, et al. Dabigatran versus warfarin in patients with atrial fibrillation. N Engl J Med. 2009; 361:1139-51.

8. Chaitman BR, Hardison RM, Adler D, Gebhart S, Grogan M, Ocampo S, et al. The Bypass Angioplasty Revascularization Investigation 2 Diabetes randomized trial of different treatment strategies in type 2 diabetes mellitus with stable ischemic heart disease: impact of treatment strategy on cardiac mortality and myocardial infarction. Circulation. 2009;120:2529-40.

9. Boden WE, O'Rourke RA, Teo KK, Hartigan PM, Maron DJ, Kostuk WJ, et al. Optimal medical therapy with or without PCI for stable coronary disease. $N$ Engl J Med. 2007;356:1503-16.

10. Wallentin L, Becker RC, Budaj A, Cannon CP, Emanuelsson H, Held C, et al. Ticagrelor versus clopidogrel in patients with acute coronary syndromes. N Engl J Med. 2009;361:1045-57.

11. Harrington RA, Stone GW, McNulty S, White HD, Lincoff AM, Gibson CM, et al. Platelet inhibition with cangrelor in patients undergoing PCI. $N$ Engl J Med. 2009;361:2318-29.

12. Bhatt DL, Lincoff M, Gibson CM, Stone GW, McNulty S, Montalescot G, et al. Intravenous platelet blockade with cangrelor during PCI. N Engl J Med. 2009;361: 2330-41. 